\title{
Table of Spin-Orbit Energies for p-Electrons in Neutral Atomic (core) np Configurations
}

\author{
W. C. Martin \\ Institute for Basic Standards, National Bureau of Standards, Washington, D.C. 20234
}

(November 23, 1970)

\begin{abstract}
Data are given in support of the recently proposed formula $\zeta_{n p} n^{* 3}=0.450 Z^{2.33} \mathrm{~cm}^{-1}(Z \geqslant 5)$. The table includes evaluations of this formula, which are probably accurate to $\sim 15$ percent for all atoms $Z=10$ to 90 . For many (core) $n p$ configurations, the accuracy of $\zeta_{n p}$ from the formula is greater than that to be expected from fitting the observed levels to intermediate coupling theory.
\end{abstract}

Key words: Atomic spectra: atomic theory: spin-orbit interaction.

\section{Introduction}

Values of the spin-orbit coupling parameter $\zeta_{n p}$ for configurations of the type (core) $n p$ in neutral atoms were recently shown to be fairly accurately reproduced for atomic numbers $Z \geqslant 5$ by the formula $[1]^{1}$

$$
\zeta_{n \mu} n^{* 3}=0.450 Z^{2.33} \mathrm{~cm}^{-1},
$$

where $n^{*}$ is the effective principal quantum number of the $n p$ electron. The relation of the $Z$-dependence of the spin-orbit interaction to its physical origin was discussed in [1]. This note gives in more detail some data supporting the formula, and evaluations of it for $Z \leqslant 90$.

\section{Values of $\zeta_{n p} n * 3$}

The dependence $\zeta_{n p} \infty 1 / n * 3$ is known to be a good approximation for simple spectra $[2,3,4]$. The change in $n^{*}$ corresponding to the fine structure splitting is thus approximately constant for a series with structure proportional to $\zeta_{n p}\left(n p{ }^{2} P\right.$ and $s n p{ }^{3} P_{2-0}$ intervals) $[2,4]$. Observations of unperturbed series of this type usually show $\Delta n *$ to be constant within $\sim 2$ percent, except for the lowest series member or two.

The constants in (1) were determined by graphically fitting the data from such series in ten spectra," indicated by stars after the element symbols in table 1. The series members that determined the value of $\zeta_{p} n * 3$ for each of these spectra are listed under the heading " $n p$ Data." These ten spectra range in atomic number from 11 to 81 , with an average disagreement of 6 percent between the observed value of $\zeta_{p} n * 3$ and

'Figures in brackets indicate the literature references at the end of this paper.

2 It is notable that the data for eight of these spectra are from accurate observations made in Lund, Sweden, during the past 15 years. the value from (1). The maximum disagreement is 12 percent.

The other data in the table are less reliable. ${ }^{3}$ Most configurations of the type (core) $n p$ with the core including a partly filled $p$ or $d$ subshell appear to be distorted by perturbations that are significant compared to $\zeta_{n p}$. The data were usually taken from the lowest such configuration, to minimize the relative error in $\zeta_{p}$. The $\zeta_{p} n * 3$ values for these lowest configurations are systematically larger than the limiting constant values (from eq (1)) by $\sim 15$ percent. At least part of this effect is understood $[3,1]$. Part of the remaining scatter in these values is probably due to configuration interactions neglected in the calculations. In some spectra there may also be uncertainty in obtaining properly corresponding values of $\zeta_{p}$ and $n *$ [1].

It seems likely that the formula values of $\zeta_{1} n * 3$ (table 1) are correct to $\sim 15$ percent for (core) $n p$ configurations ( $n$ greater than any principal quantum number in the core) in all atoms $Z=10$ to 90 . This accuracy must of course not be expected if perturbation has affected the value of $n^{* 3}$ by more than a few percent. Any other large percentage deviations from the formula are suspect and probably unphysical. In many cases rather complete and detailed calculations would be necessary to obtain values of $\zeta_{p}$ by the levelfitting method as accurate as the formula values. It would thus be advantageous in some instances to fix this parameter.

Some examples of these various points may be inferred from table 2 , where values of $\zeta_{p}$ obtained by different methods for several rare-gas configurations are compared. The smaller values of $\zeta_{p}$, as in $\mathrm{Ne}$, are

${ }^{3}$ Only a representative selection of the data available from complex spectra is given in the table. The $\zeta_{\mu} n^{* 3}$ values listed for the first few elements following hydrogen are not accurate, since other interactions that contribute significantly to the term intervals were not allowed for. The results and discussion are not applicable for $Z<5$. 
TABLE 1. Values of $\zeta n^{* 3}$ for np-electrons in configurations of the type (core) np.

The data are from neutral atoms with the core-configurations shown. A core with electrons of different $n l$ indicates that configuration interaction was included in the calculation. Where more than one $n p$ electron is shown in the fourth column, the value in the fifth column is an average. References for data or calculations are indicated by letters in parentheses in the fourth column. The other experimental values of $\zeta n^{* 3}$ are based on data from Atomic Energy Levels [C. E. Moore, Nat. Bur. Stand. (U.S.), Circ. 467, Vol. I (1949); Vol. II (1952); Vol. III (1958)].

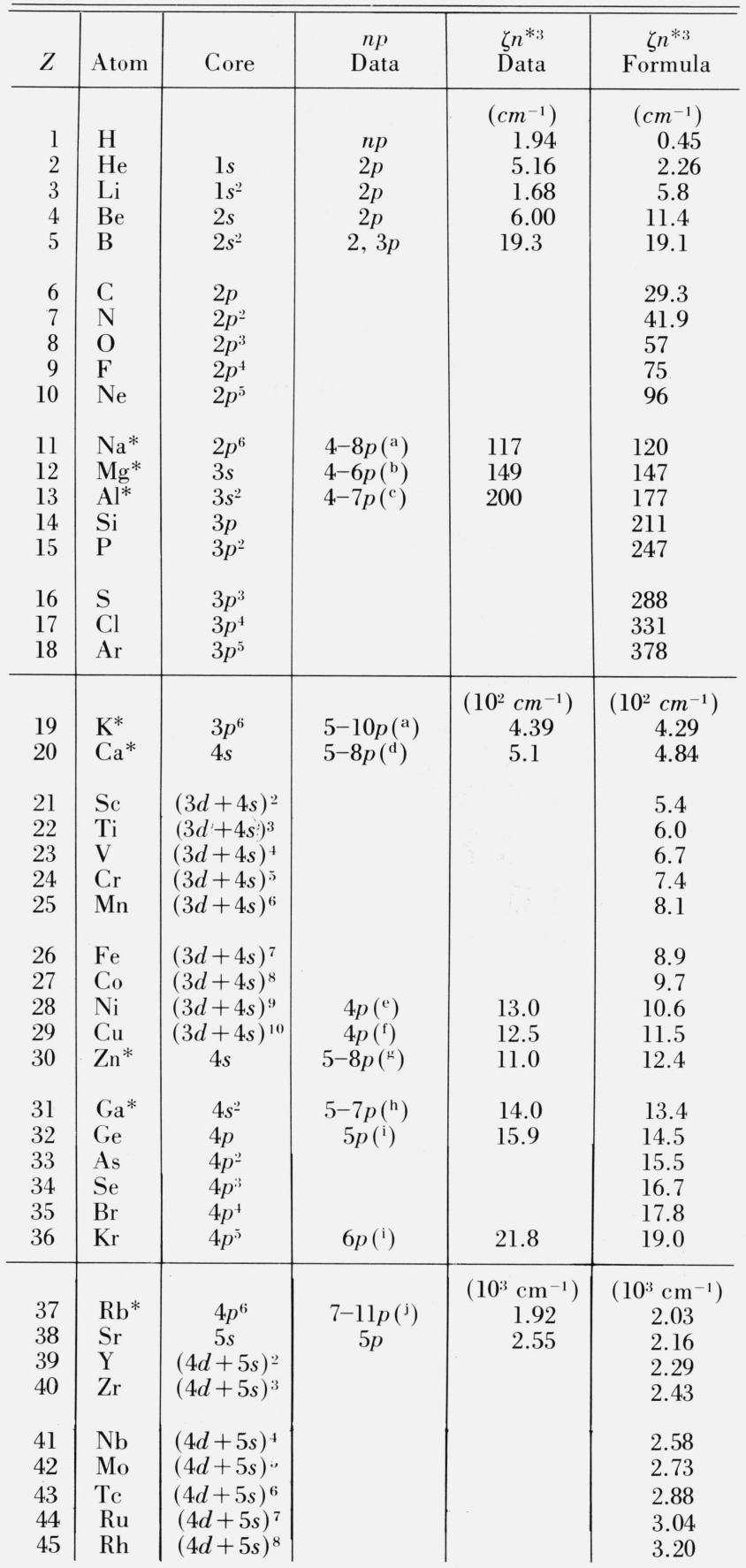

\begin{tabular}{|c|c|c|c|c|c|}
\hline$Z$ & Atom & Core & $\begin{array}{c}n p \\
\text { Data }\end{array}$ & $\begin{array}{l}\zeta n^{* 3} \\
\text { Data }\end{array}$ & $\begin{array}{c}\zeta n^{* 3} \\
\text { Formula }\end{array}$ \\
\hline & & & & $\left(10^{3} \mathrm{~cm}^{-1}\right)$ & $\left(10^{3} \mathrm{~cm}^{-1}\right)$ \\
\hline 46 & $\mathrm{Pd}$ & $(4 d+5 s)^{9}$ & & & 3.37 \\
\hline 47 & $\mathrm{Ag}$ & $4 d^{10}$ & $6 p$ & 3.47 & 3.54 \\
\hline 48 & $\mathrm{Cd}$ & $5 s$ & $6 p$ & 3.58 & 3.72 \\
\hline 49 & In & $5 s^{2}$ & $6,7 p\left({ }^{\mathrm{h}}\right)$ & 3.99 & 3.90 \\
\hline 50 & Sn & $5 p$ & & & 4.09 \\
\hline 51 & $\mathrm{Sb}$ & $5 p^{2}$ & & & 4.28 \\
\hline 52 & $\mathrm{Te}$ & $5 p^{3}$ & & & 4.48 \\
\hline 53 & I & $5 p^{4}$ & & & 4.69 \\
\hline 54 & $\mathrm{Xe}$ & $5 p^{5}$ & $6 p\left({ }^{k}\right)$ & 4.79 & 4.89 \\
\hline 55 & $\mathrm{Cs}^{*}$ & $5 p^{6}$ & $8-13 p$ & 4.74 & 5.1 \\
\hline 56 & $\mathrm{Ba}$ & $6 s$ & $6 p$ & 6.1 & 5.3 \\
\hline 57 & $\mathrm{La}$ & $(5 d+6 s)^{2}$ & & & 5.6 \\
\hline 58 & $\mathrm{Ce}$ & & & & 5.8 \\
\hline 59 & $\operatorname{Pr}$ & & & & 6.0 \\
\hline 60 & $\mathrm{Nd}$ & $4 f^{4} 6 s$ & & & 6.3 \\
\hline 61 & $\mathrm{Pm}$ & $4 f^{5} 6 s$ & & & 6.5 \\
\hline 62 & $\mathrm{Sm}$ & $4 f^{6} 6 s$ & & & 6.8 \\
\hline 63 & $\mathrm{Eu}$ & $4 f^{7} 6 s$ & $6 p\left({ }^{1}\right)$ & 8.3 & 7.0 \\
\hline 64 & Gd & $4 f^{7} 5 d 6 s$ & & & 7.3 \\
\hline 65 & $\mathrm{~Tb}$ & & & & 7.5 \\
\hline 66 & Dy & $4 f^{10} 6 s$ & & & 7.8 \\
\hline 67 & Но & $4 f^{11} 6 s$ & & & 8.1 \\
\hline 68 & Er & $4 f^{12} 6 s$ & & & 8.4 \\
\hline 69 & $\mathrm{Tm}$ & $4 f^{13} 6 s$ & & & 8.7 \\
\hline 70 & $\mathrm{Yb}$ & $6 s$ & $6 p$ & 10.5 & 9.0 \\
\hline 71 & $\mathrm{Lu}$ & $(5 d+6 s)^{2}$ & & & 9.3 \\
\hline 72 & $\mathrm{Hf}$ & $(5 d+6 s)^{3}$ & & & 9.6 \\
\hline 73 & $\mathrm{Ta}$ & $(5 d+6 s)^{4}$ & & & 9.9 \\
\hline 74 & W & $(5 d+6 s)^{5}$ & & & 10.2 \\
\hline 75 & $\operatorname{Re}$ & $(5 d+6 s)^{6}$ & & & 10.5 \\
\hline 76 & Os & $(5 d+6 s)^{7}$ & & & 10.9 \\
\hline 77 & $\operatorname{Tr}$ & $(5 d+6 s)^{8}$ & & & 11.2 \\
\hline 78 & $\mathrm{Pt}$ & $(5 d+6 s)^{9}$ & & & 11.5 \\
\hline 79 & $\mathrm{Au}$ & $5 d^{10}$ & $6 p$ & 14.4 & 11.9 \\
\hline 80 & $\mathrm{Hg}$ & $6 s$ & $6 p$ & 17.8 & 12.2 \\
\hline 81 & $\mathrm{Tl}^{*}$ & $6 s^{2}$ & $7-11 p$ & 13.4 & 12.6 \\
\hline 82 & $\mathrm{~Pb}$ & $6 p$ & & & 13.0 \\
\hline 83 & $\mathrm{Bi}$ & $6 p^{2}$ & & & 13.3 \\
\hline 84 & $\mathrm{Po}_{0}$ & $6 p^{3}$ & & & 13.7 \\
\hline 85 & At & $6 p^{4}$ & & & 14.1 \\
\hline 86 & $\mathrm{Rn}$ & $6 p^{5}$ & & & 14.5 \\
\hline 87 & $\mathrm{Fr}$ & $6 p^{6}$ & & & 14.9 \\
\hline 88 & Ra & $7 s$ & $7,8 p$ & 18.2 & 15.3 \\
\hline 89 & Ac & $(6 d+7 s)^{2}$ & & & 15.7 \\
\hline 90 & Th & & & & 16.1 \\
\hline
\end{tabular}

${ }^{a}$ Risberg, P., Arkiv Fysik 10, 583 (1956).

${ }^{\mathrm{b}}$ Risberg, G., Arkiv Fysik 28, 381 (1965).

' Eriksson, K. B. S., and Isberg, H. B. S., Arkiv Fysik 23, 527 (1963).

${ }^{\mathrm{d}}$ Risberg, G., Arkiv Fysik 37, 231 (1968).

e Roth, C., J. Res. Nat. Bur. Stand. (U.S.), 74A (Phys. and Chem.) 715-722 (Sept.-Oct. 1970).

${ }^{\mathrm{f}}$ Landman, D. A., Levin, L. A., and Lurio, A., J. Opt. Soc. Am. 59, 962 (1969).

Johansson, I., and Contreras, R., Arkiv Fysik 3 7, 513 (1968).

h Johansson, I., and Litzén, U., Arkiv Fysik 34, 573 (1967).

${ }^{i}$ Cowan, R. D., and Andrew, K. L., J. Opt. Soc. Am. 55, 502 (1965).

${ }^{\mathrm{j}}$ Johansson, I., Arkiv Fysik 20, 135 (1961).

k Liberman, S., J. phys. 30, 53 (1969).

' Smith, G., and Wybourne, B. G., J. Opt. Soc. Am. 55, 121 (1965). 
TABLE 2. Values of spin-orbit energy for np electrons in some rare-gas configurations.

The "formula" values of $\zeta_{m,}$ (from $\zeta n^{*}$ in table 1 ) are probably accurate to 15 percent.

\begin{tabular}{|c|c|c|c|c|c|}
\hline \multirow{2}{*}{\multicolumn{2}{|c|}{ Core }} & \multirow[b]{2}{*}{$n p$} & \multirow[b]{2}{*}{$n^{*}$} & \multicolumn{2}{|r|}{$\zeta_{\mu \mu}, \mathrm{cm}^{-1}$} \\
\hline & & & & Formula & $\begin{array}{l}\text { Level-fitting } \\
\text { Calculations }\end{array}$ \\
\hline Ne & $2 y .5$ & $\begin{array}{l}3 p \\
4 p \\
5 p \\
6 p\end{array}$ & $\begin{array}{l}2.154 \\
3.163 \\
4.165 \\
5.165\end{array}$ & $\begin{array}{l}9.6 \\
3.0 \\
1.33 \\
0.70\end{array}$ & $\begin{array}{c}\text { a } 40.0, " 13 \pm 60 \\
\text { " } 1 \pm 12 \\
\text { : } 8.1 \\
\text { a } 5.4\end{array}$ \\
\hline $\mathrm{Ar}$ & $3 p^{3}$ & $\begin{array}{l}4 p \\
5 p \\
6 p\end{array}$ & $\begin{array}{l}2.279 \\
3.306 \\
4.310\end{array}$ & $\begin{array}{r}32 \\
10.5 \\
4.7\end{array}$ & 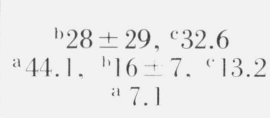 \\
\hline $\mathrm{Kr}$ & $4 p^{5}$ & $\begin{array}{l}5 p \\
6 p\end{array}$ & $\begin{array}{l}2.322 \\
3.356\end{array}$ & $\begin{array}{r}152 \\
50\end{array}$ & $\begin{array}{c}\text { а } 246, \text {, } 159 \pm 25 \\
\text { а } 49.0, \text { " } 58 \pm 9\end{array}$ \\
\hline$X_{e}$ & $5 y$ & $6 p$ & 2.383 & 361 & a 374, d 353.7 \\
\hline
\end{tabular}

\footnotetext{
a Condon, E. U., and Shortley, (. H., The Theory of Atomic Spectra, pp. 306-312 (Cambridge, 1953). Some of these values were quoted from earlier calculations, with references given.

b Cowan. R. D., and Andrew. K. I... J. Opt. Soc. Am. 55, 502 (1965).

"Garstanж. R. H., and Van Blerkom. J.. J. Opt. Soc. Am. 55 , $1054(1965)$.

"Liberman. S.. J. Phys. 30, 53 (1969). Calculation includes interaction with $.5,57 \%$
}

relatively more sensitive to distortion by perturbations in level-fitting determinations.

The core configurations listed in table 1 are the lowest for each element. (A few of the cores that have low levels of both parities are not listed.) However, the value of $\zeta_{n}$, is only weakly affected by core excitation for most configurations observed in optical spectroscopy. Values of $n^{*}$ for a particular $n p$ ( $n$ greater than for any core electron) but based on different core configurations will normally differ by fairly small amounts if the configurations involved are unperturbed. The most reliable experimental values of $n *$ are usually obtained from terms based on the core configurations in the table.

The available data would probably yield useful relations for the $Z$-dependence of $\zeta_{p} n^{* 3}$ in ionized spectra. Both this and the probably more troublesome extension to higher $l[1]$ would merit investigation.

\section{References}

[1] Fano, U., and Martin. W. C.. in Topics in Modern Physics, A Tribute to E. U. Condon (Brittin, W. E., and Odabasi, H., eds., Colorado Associated University Press, 1971).

[2] I.andé. A., Z. Physik 25, 46 (1924)

3] Casimir. H. B. G.. Arch. Musée Teyler. Series 3, 8, 201 (1936).

[4] Edlén. B.. "Atomic Spectra" in Encyclopedia of Phvsics, S. Flügge, Ed., Vol. 27, pp. 129-130 (Springer-Verlag, Berlin, 1964.

(Paper 75A2-653) 